\title{
REVIEW
}

\section{Wildlife DNA forensics - bridging the gap between conservation genetics and law enforcement}

\author{
Rob Ogden ${ }^{1,2, *}$, Nick Dawnay ${ }^{2}$, Ross McEwing ${ }^{1,3}$ \\ ${ }^{1}$ Wildlife DNA Services, Tepnel Research Products and Services, Appleton Parkway, Livingston EH54 7EZ, UK \\ ${ }^{2}$ School of Biological Sciences, Bangor University, Deiniol Road, Bangor LL57 2UW, UK \\ ${ }^{3}$ TRACE Wildlife Forensics Network, Science Campus, Deiniol Rd, Bangor LL57 2UW, UK
}

\begin{abstract}
Wildlife DNA forensics is an applied field that has emerged from a synthesis of conservation genetic research and forensic genetic practice to meet the increasing need for investigative tools in wildlife law enforcement. This review describes the principal technologies and applications available to wildlife forensic geneticists, focussing on the four most common casework questions: What species is it? Where did it come from? Who did it come from? Was it captive bred? The conversion of established research tools into forensic identification systems is discussed, explaining the need for method validation at each stage of the analytical process, from sample collection to data analysis. The requirement for wildlife DNA forensic analysis to be performed under equivalent quality assurance standards to those of human forensic genetics is highlighted and approaches for the interpretation and presentation of DNA evidence are described. A perspective is provided on the potential for new genetic techniques and their future role in the increasingly complex fight to enforce the protection of endangered species. The review concludes with a number of recommendations for promoting a unified, rigorous approach to the development and application of wildlife DNA forensic techniques.
\end{abstract}

KEY WORDS: Wildlife crime $\cdot$ Legal - Illegal trade Poaching CITES $\cdot$ Species identification · DNA profiling $\cdot$ Population assignment

\section{INTRODUCTION}

The field of conservation genetics has developed over the past $20 \mathrm{yr}$ to support the application of molecular genetic analysis to problems and questions encountered in species conservation. Research is primarily undertaken by academic scientists and has led to new approaches for the collection, analysis and interpretation of biological samples in addition to generating information relevant to the management of target populations. The breadth of possible applications requires conservation geneticists to draw on a wide range of established biological subjects including pop- ulation genetics, molecular ecology, molecular phylogenetics, phylogeography and taxonomy. Their principal objective is to synthesize this knowledge and develop best practice solutions to specific challenges faced in conservation (Frankham et al. 2002).

One area of conservation genetics that has long been recognized but is now receiving increasing attention is the development of analytical techniques capable of providing DNA evidence to assist in conservation law enforcement, commonly termed 'wildlife DNA forensics'. Wildlife DNA forensics is essentially concerned with the identification of evidence items in order to determine the species, population, relationship or indi- 
vidual identity of a sample. The subject has developed in parallel to human forensic genetics and has benefited from the horizontal transfer of molecular and statistical techniques; however, it remains a highly specialist area with its own distinct set of challenges, situated between wildlife conservation research and applied forensic science. With the development of national and international legislation to protect everdiminishing habitat and species diversity, DNA forensics is now becoming a key investigative tool to combat wildlife crime. At the same time, the way in which DNA evidence is generated and presented in court is coming under renewed scrutiny. This review introduces the subject of wildlife DNA forensics, highlighting the potential advantages and pitfalls surrounding this emerging field, and aims to provide recommendations for promoting a unified, rigorous approach to the development and application of wildlife DNA forensic techniques.

\section{HISTORY}

The use of genetic analysis to identify non-human evidence began shortly after the first DNA fingerprints were applied to human forensic investigation (Gill et al. 1985). The realization that the same technique could allow familial identification in birds (Burke \& Bruford 1987) rapidly led to the use of these methods to verify captive breeding claims in cases where wild bird theft was suspected (Shorrock 1998). The development of individual DNA identification systems has since followed that of human methods through the use of multilocus (Thommasen et al. 1989) and single-locus (Wetton \& Parkin 1997) probes and microsatellites (Jones et al. 2002, Singh et al. 2004, Xu et al. 2005). In parallel to this research, DNA also began to be used to identify the species from which trace evidence originated (Cronin et al. 1991, Parson et al. 2000). This application relied on molecular taxonomy rather than human forensic techniques and proved particularly useful for investigating cases of illegal trade (Baker et al. 1996, Baker \& Palumbi 1994) and poaching (Guglich et al. 1994, Sweijd et al. 1998).

Today we can see a wide array of molecular identification techniques applied in many countries to evidence originating from a diverse range of taxa. This expansion offers huge potential for the conservation of endangered species but at the same time presents multiple challenges to those attempting to transfer research methods into forensic analytical tools. Perhaps the most pressing issue of all is the need to find an acceptable balance between the utilization of academic research to drive the development of genetic identification techniques, and the expectations and requirements of the forensic science community to present clear, unequivocal evidence produced using validated, robust methods. In many ways, the field of wildlife DNA forensics is undergoing the same process of gradual incorporation into law enforcement that human DNA forensics underwent in the late 1980s and early 90s. During this period of time, the initial acceptance of DNA evidence was followed by a series of challenges that led to the re-evaluation of many forensic genetic practices (Lander 1989, Lander \& Budowle 1994). It is important that the lessons learnt from these experiences are transferred to wildlife forensic genetics, in order to avoid evidence being dismissed from courtrooms and the subsequent loss of credibility to the field. One of the objectives of this study is to raise awareness of these issues and communicate the need for conservation genetic researchers to keep in mind the implications of their work.

\section{SPECIES PROTECTION AND LAW ENFORCEMENT}

In recent years the law enforcement community has observed increasing links between wildlife crime and organized crime. The illegal trade in flora and fauna offers financial rewards comparable to those of the narcotics trade with only a fraction of the risk, and thus attracts the attention of international criminal organizations. Such activities clearly threaten the survival of critically endangered target species, for example tiger, rhinoceros and mahogany; however, they also reduce our ability to sustainably harvest more abundant species, pushing them towards extinction and threatening global economic markets such as the fishing and timber industries. This new understanding has added weight to the long-held position of conservationists regarding the need to legally protect global biological resources.

Legislation for the protection of specific species and the strength with which any such laws are enforced varies widely among countries. Internationally, the Washington Convention on International Trade in Endangered Species of Wild Fauna and Flora (CITES), provides a framework for trade control and monitoring; however, each of the current 173 member states is responsible for implementation of the convention through national law. National laws generally extend beyond CITES to include species conservation within each country, controlling exploitation and trade at a domestic level. For example, in the USA, the Endangered Species Act (ESA) describes federal wildlife laws for both national conservation and international trade. Any application of wildlife DNA forensic analysis must be directly related to the legislation being 
enforced and, conversely, any new legislation relating to biological identification must be enforceable, making it important to develop a reciprocal understanding between wildlife legislators, law enforcers and forensic scientists.

The purpose of any forensic analysis is to provide information or evaluate hypotheses concerning the evidence available. This means that analysis is driven by the questions asked by casework investigators. Individual cases generate individual questions; however, in wildlife law enforcement most forensic enquiries can be divided into 4 main problems: what species is it from, where is it from, who did it come from and was it captive bred? Each of these questions can be considered in wildlife DNA forensics using a variety of different techniques; the following section examines the methods associated with each one.

\section{FORENSIC GENETIC IDENTIFICATION METHODS}

\section{Species identification}

The use of genetic analysis to identify the species of an evidence sample is the most common application in wildlife DNA forensics. Species identification may be used in cases of illegal poaching in order to identify trace evidence in the field or from a suspect's possessions (Gupta et al. 2005). It has also been widely applied to the identification of traded products that have lost identifying morphological characters, such as processed wood (Deguilloux et al. 2002), traditional medicines (TMs) (Hsieh et al. 2003, Wetton et al. 2004, Peppin et al. 2008) and shark fins (Shivji et al. 2002, Chapman et al. 2003).

Genetic species identification relies on the isolation and analysis of DNA markers that show variation among species, but are generally conserved within species. In animals, the most commonly used markers are gene regions within mitochondrial DNA, particularly cytochrome $b$ (Parson et al. 2000) and cytochrome oxidase subunit I (COI) (Hebert et al. $2003 a, b)$, as their mutation rates roughly coincide with the rate of species evolution. In plants, suitable genetic markers are normally found in the chloroplast genome within genes such as matK and trnH-psbA (Kress et al. 2005). Due to the presence of multiple mitochondrion and chloroplast organelles within a single cell, these markers are present in multiple copies. In comparison to nuclear DNA, where in diploid species a single nucleus carries just 2 copies of each marker, this increases the chance of success when analyzing trace evidence samples that typically contain relatively little cellular material (Butler \& Levin 1998, Budowle et al. 2003).
In practice, there are several techniques used to analyze species informative markers (Box 1). The principal method is DNA nucleotide sequencing, followed by comparison of the resulting sequence with reference sequence data from different species. The level of similarity between test and reference sequences enables the species of origin to be inferred. DNA sequencing has been approved for use by the International Society for Forensic Genetics (ISFG) (Carracedo et al. 2000, Bär et al. 2000) and has been validated as a technique for use in forensic identification casework (Wilson et al. 1995). A particular advantage associated with sequencing is that universal PCR primers can be employed enabling the amplification of DNA from a wide range of species without any prior information regarding the sample (Verma \& Singh 2003).

The primary method of identifying a DNA sequence is through the use of a reference database search whereby the unknown sequence is compared to those of known samples: a measure of the similarity between sequences is calculated and the most similar species is attributed to the sample (Parson et al. 2000, Branicki et al. 2003). The most commonly used reference databases for comparative species identification searches are the NCBI/EMBL/DDBJ database collaboration (www.insdc.org) and BOLD, part of the Consortium for the Barcoding of Life (CBOL, www.barcodinglife.com). For species that are well represented in such public databases it is common to encounter a $100 \%$ sequence match between the unknown sample and its reference species. However, due to sequence variation within species, no exact match may be observed, resulting in a species identification based on, for example, a $98.5 \%$ match. Closely related species may have sequence similarities of 90 to $95 \%$, or higher. The total length of the sequence which is being matched also affects the confidence of identification. It is therefore left to the experience and judgement of the forensic scientist to evaluate the strength of evidence when undertaking a sequence similarity match.

An alternative analysis method for species identification is the construction of a phylogenetic tree. The tree is used to discern the evolutionary relationships between the test sample and reference sequences from each possible species (Avise 1994, Roman \& Bowen 2000, Verma et al. 2003). The position of the test sample in the tree allows the closest reference species to be identified as the likely source. However, there are several different methods for constructing phylogenetic trees (e.g. neighbor-joining, maximum parsimony, maximum likelihood, Bayesian; see Holder \& Lewis (2003) for overview) and there is currently no consensus in wildlife forensic science over which to use (Terol et al. 2002, Wong et al. 2004). Both the tree topology (branching pattern) and associated support 
Box 1. Introduction to the current techniques used in wildlife DNA forensics

\section{DNA nucleotide sequencing}

Sequencing identifies each nucleotide (base) within a specific target region of DNA (the genetic marker). Species identification usually involves sequencing around 500 bases of DNA to provide a species-specific sequence. Sequencing provides data for developing genetic markers such as single nucleotide polymorphisms (SNPs) microsatellites and InDels, which describe specific areas of sequence variation. (a) Four DNA sequences of 16 bases in length; the three reference sequences differ, the unknown sequence matches Ref. 2

\begin{tabular}{|c|c|c|c|c|c|c|c|c|}
\hline Ref. 1 & $\mathbf{T A} \mathbf{T}$ & $T C$ & $C A T A$ & $\mathrm{C}$ & ] $\mathrm{T}$ A & I C & & G \\
\hline Ref. 2 & T A T & $T C$ & C $T$ T A & $T$ & A T A & C & & G \\
\hline Ref. 3 & T A C & $T C$ & $C \quad T \quad T A$ & C & A $T A$ & A $c$ & & G \\
\hline Unknown & T A T & $T C$ & $C \quad T \quad T A$ & $\mathrm{~T}$ & A T A & A $C$ & & G $A$ \\
\hline
\end{tabular}

Single base differences are known as SNPs. Individual variants (e.g. C or T) are referred to as 'alleles'

\section{SNP typing}

SNP typing, or genotyping, allows specific variable sites in a DNA sequence to be investigated. Focussing on a SNP site allows faster, cheaper tests to be developed that do not require such long fragments of high quality DNA, however less information is gained in comparison to DNA sequencing. There are multiple methods for typing SNP markers; 3 examples used in DNA forensics are provided below:

\section{(i) PCR-RFLP}

PCR-RFLP relies on the ability of enzymes to cut DNA at specific recognition sites. Where these sites coincide with a SNP marker, some sequences will be cut to produce 2 DNA fragments (S1), others will not (S2), leading to differences in the number and length of DNA fragments between samples. These differences can be resolved under electrophoresis.

\section{(ii) Allele-specific PCR}

Primers used in PCR for amplifying genetic markers can be designed for conserved regions of DNA (universal primers) or regions where DNA varies between species or populations (allele specific primers). Allele specific primers are designed so that PCR only works when DNA from the target sequence is present in a sample.

\section{(iii) Allele-specific probes}

An alternative to using specific primers is to use universal primers in combination with a specific probe. Different probes are designed to attach to different DNA sequence variants (S1 and S2) allowing the base present at a SNP site to be detected.

\section{Microsatellite genotyping}

Microsatellite markers describe differences between DNA sequences due to variation in the number of repetitive units of DNA in a specific region. Changes in the repeat number lead to different sized DNA fragments (alleles) that can be resolved under electrophoresis. (b) Enzyme recognition site only present in S1, therefore only S1 DNA is cut

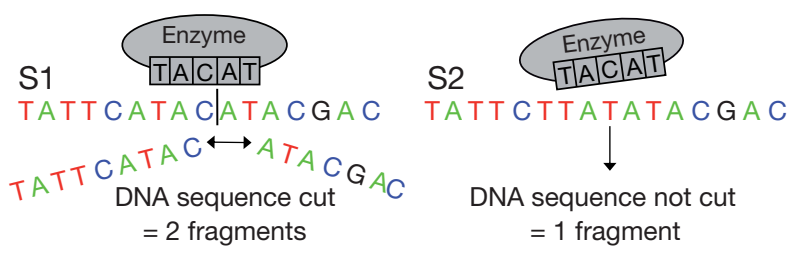

(c) Complimentary primer only binds to target DNA sequence (S1), enabling amplification
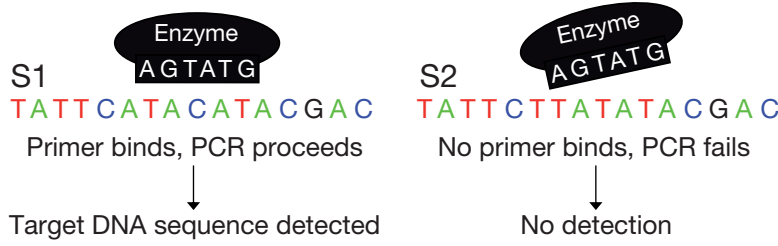

(d) PCR amplification with universal primers (UP)

PCR amplification of both sequences with universal primers (UP)

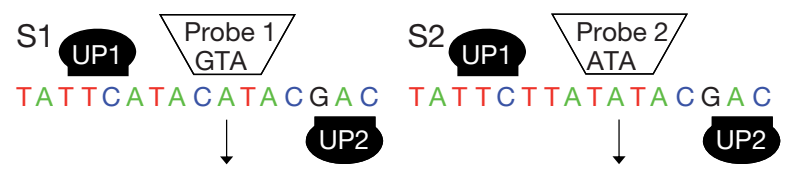

Allele specific probes detect target sequence differences (SNPs)

(e) The number of repeat units (ACAT) varies between the 2 samples, altering the length of the DNA fragments (microsatellite alleles)

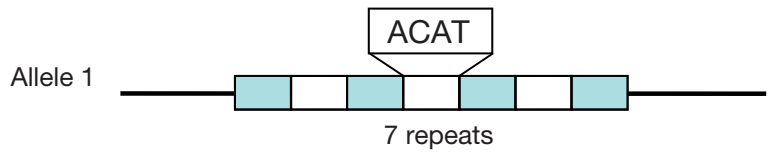

Allele 2

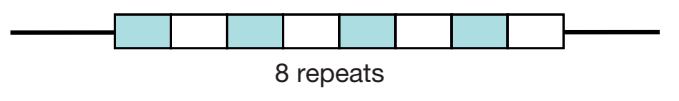


may differ among construction methods, complicating the presentation of such evidence to a jury and requiring forensic practitioners to take great care in the interpretation of their results.

The differences observed among species at a genetic marker are largely due to single base pair changes in the DNA sequence, known as single nucleotide polymorphisms (SNPs) (Box 1). SNPs can be directly utilized to identify species, without the need for full sequencing, using a number of techniques that are either more cost-effective and low-tech, for example PCR-restriction fragment length polymorphism (RFLP) (Box 1) (Tahir et al. 1996, Hold et al. 2001), or enable analysis of shorter DNA sequence regions via SNP genotyping. Minimizing the size of the genetic marker targeted is often necessary to obtain results from samples that are either degraded or have been highly processed, fragmenting the DNA (Butler et al. 2003, Hajibabaei et al. 2006).

By reducing the genetic information available from an entire sequence to the characterization of several SNPs within the genetic marker, there is an increased risk of sample misidentification that must be considered when designing assays and interpreting forensic data. Both PCR-RFLP and SNP-genotyping methods are widely accepted within the forensic genetic community, however they are applied in the context of species detection, rather than species identification. SNP genotyping assays will have a defined scope that describes the total set of species that have been tested during development. The application of such a test therefore assumes knowledge of the potential species present, with the aim of discriminating among them it does not exclude the possibility that other non-target species are present. This theoretically allows for a positive result for a target species being generated from a non-target species that was not included in the original assay design. This issue drives the definition of the total species set; from a scientific perspective it requires inclusion of phylogenetically related (evolutionarily similar) species; from a forensic perspective it requires inclusion of species that could reasonably be expected to be found in place of the target species. For example, the development of an assay to detect the CITES-listed tropical hardwood genus Gonystylus (ramin), included species from all con-familial genera and a further 17 unrelated species that were known to occur in the timber trade and could conceivably have been misidentified as ramin on the basis of morphology (Ogden et al. 2008, this Theme Section). While this may seem odd to someone with a background in evolutionary genetics, it is crucial to the defence of forensic interpretation in court.

Although the development of assays that target SNPs rather than generate whole sequences restricts their scope to species detection, it does allow the analysis of samples where multiple species are present, in contrast to DNA sequencing with universal primers. The detection of DNA from endangered species in TMs that may contain multiple animal and plant derivatives has been achieved using allele-specific PCR primers and probes (DeSalle \& Birstein 1996, Wan \& Fang 2003, Wetton et al. 2004, Imaizumi et al. 2007) (Box 1). The development of multiplex assays that can simultaneously detect any species from a target set is increasing the utility of these approaches (Tobe \& Linacre 2008). The recent transfer of array-based genotyping methods from human to non-human research has led to the development of SNP assays for the simultaneous detection of large numbers of target species (Kochzius et al. 2008) and it is anticipated that this technology will soon become available to the wildlife forensic community.

The power to identify species offered by DNA sequencing and the ability to analyze mixed DNA through SNP approaches can be combined. By using species-specific PCR-primers it is possible to generate a single DNA sequence for the target species from a sample containing multiple species DNA. This sequence can then be identified to species level to categorically demonstrate its presence in the sample and is therefore a favoured method in wildlife DNA forensics. Applications include the identification of bear bile in TMs (Peppin et al. 2008) and shark body parts (Chapman et al. 2003).

\section{Identification of geographic origin}

Wildlife legislation usually operates within political boundaries such as national and regional borders or marine fishery zones. Species distributions are governed by biological and environmental factors that rarely coincide with such legislation. This mismatch often leads to wildlife crime investigations asking questions concerning the geographic origin of a sample. For example, to enforce CITES regulations it may be necessary to demonstrate the geographic source of a specific sample, in addition to identifying the species. Similarly, the effective management of marine protected areas requires methods that enable illegally harvested stocks to be distinguished from those taken legally from elsewhere. Genetic analysis has been employed to infer geographic origin of samples in biological research for many years; however, the number of published studies detailing the application of these tools to forensic casework is low, suggesting this arena is in its infancy.

From a forensic genetic perspective, identifying the geographic origin of a sample is equivalent to identi- 
fying its reproductive population of origin. Biological populations include many different levels of genetic variation, from extended families to subspecies, making them difficult to define. Populations are often capable of sharing genetic material, therefore compared to species identification, DNA markers are less likely to show discrete differences among groups (Fig. 1). Geographic origin identification is based on our ability to assign a sample to a particular population, requiring the source population to be sufficiently genetically distinct from other candidate populations and relying on the existence of population data from multiple areas. Despite these limitations, a wealth of existing academic and conservation management research focussing on population assignment is now being transferred to address the urgent need for enforcement techniques capable of identifying geographic origin. The methods employed are largely dictated by the degree of genetic differentiation between populations.

Within some species, populations may be so isolated from one another that there is effectively no exchange of genetic material between them. Genetic differences will gradually accumulate over evolutionary time to a point where members of an isolated region share the same types of genetic marker (alleles) within their population, but exhibit different alleles to that of any other population. Markers that exhibit such discrete variation are very useful for identifying populations and therefore for assigning an individual to a geographic region with a high degree of confidence (Fig. 1). In

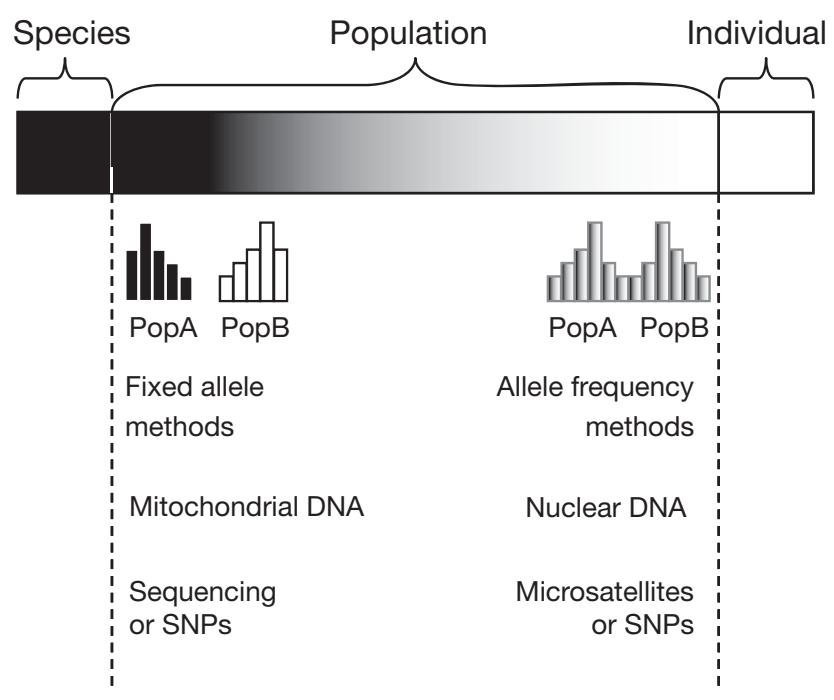

Fig. 1. The level of genetic diversity between populations exhibits continuous variation, from subspecies (dark end) to extended families (light end). The degree of population (Pop) divergence dictates the selection of genetic markers and subsequent analytical methods used to assign a sample to its geographic origin. SNPs: single nucleotide polymorphisms highly divergent populations, mitochondrial DNA (mtDNA) can be used to identify populations, similar to species identification. The hypervariable mtDNA control region, or D-loop, is often used as a marker in geographic origin identification, with individual control region sequence types ('haplotypes') corresponding to specific populations. Wu et al. (2005) applied this technique to the Chinese sika deer Cervus nippon that is classified into 4 subspecies. Following widespread hunting to supply the TM trade, 2 sub-species were extirpated (lost) from the wild and now exist only in captivity where they are bred in large numbers for medicinal use. The remaining 2 subspecies that exist in the wild are very seriously threatened and heavily protected by Chinese law. In order to enforce this conservation legislation, a method to discriminate one of the wild subspecies from one of the domesticated subspecies was developed, based on mtDNA control region haplotype variation.

In the absence of sufficient mitochondrial DNA variation, it is necessary to employ genetic markers from the nuclear genome that show variability among regions. Although some microsatellite and SNP markers (Box 1) do show discrete differences, individual alleles will often be distributed across populations (Fig. 1). This means that differentiation can only be achieved on the basis of differing allele frequencies. The frequency of the alleles observed in a population can be used to characterize its genetic structure and to assess the probability of a sample originating from that area. Such probabilistic approaches have 2 important implications for wildlife forensic investigations. First, it is necessary to develop large genetic databases to provide representative allele frequencies for all of the potential source populations. Second, it requires the use of statistical analysis to provide quantitative probabilities of assignment for a sample to each of those populations.

In practice, a DNA profile is first generated from a test sample using a panel of genetic markers. The profile is then assigned to a population by comparing the alleles observed in the profile with the allele frequencies observed in the populations. There is a wide range of analytical methods available for assignment (reviewed by Manel et al. 2005) and it is important to understand the statistical basis and underlying assumptions of any that are used. In a forensic context it is necessary to select a method that enables the scientist to evaluate both prosecution and defence hypotheses; that is, one which provides a quantitative estimate of the probability that the sample originated from the source claimed by the defence, rather than simply identifying the most likely genetic geographic origin. Assignment tests are normally implemented in software packages, and a number are freely available 
for data analysis (reviewed by Hauser et al. 2006). Population assignment is extensively used to prosecute illegal salmon fishing in the NW Pacific (Withler et al. 2004), where large databases have been established (Seeb et al. 2007), but applications are currently limited for endangered species where data are difficult to collect.

In populations that exhibit much larger rates of gene exchange, allele frequencies among different regions may be almost equal at neutral genetic markers, making it impractical to apply this approach to identify the geographic origin of wildlife samples. This may occur where a population has been defined by non-biological criteria, such as fishing zones drawn along geopolitical boundaries, or nationally certified timber products obtained from species with wind-dispersed pollen. In both these examples, there is no biological restriction to the dispersal of genes across multiple 'populations' and exact geographic origin cannot be described. Where genetic populations are widely distributed, non-genetic alternatives, such as stable isotopes (Benson et al. 2006) may be more suitable to determine the source of biological material.

\section{Individual identification}

The use of DNA profiling for the individual identification of genetic evidence has revolutionized human forensic analysis over the past 20 yr. In contrast, the identification of individual animals and plants has often been less relevant to the protection of endangered species. However, for certain issues such as poaching, where it may be necessary to demonstrate that a horn, tusk, bone or skin has originated from a specific individual, DNA profiling techniques can provide key evidence to wildlife crime investigations. Other applications include the identification of stolen animals and the authentication of legally traded wildlife products.

DNA profiling works by targeting genetic markers that are highly variable within species and are therefore likely to show differences among individuals. As with geographic origin identification, multiple microsatellite or SNP markers are used to create a profile that consists of a series of alleles (Box 1). The greater the number of markers used, the less likely it is that another individual has the same series of alleles (same profile). If 2 samples produce different DNA profiles, the possibility that they originate from the same individual can be excluded. If 2 samples share the same profile, it suggests that they may come from the same individual and it is then necessary to calculate the probability that 2 individuals have the same profile by chance. This probability is affected by the number and variability of markers in the profile, how common the alleles are in the species (their frequency), and how closely related individuals are in the population where the samples were taken. Evaluating these factors requires a representative sample of DNA profiles from the population.

The development of individual profiling techniques for wildlife DNA forensic investigation has been limited by the need to generate reference data; however, examples of successful applications do exist. In Canada, DNA profiling systems have been developed and are regularly applied to support investigations into the poaching of mule deer Odocoileus heimonus, white-tailed deer $O$. virginianus, elk Cervus canadiensis, moose Alces alces, caribou Rangifer tarandus and black bear Ursus americanus (www.forensicdna.ca/ dnadatabases.html). In northern Italy, evidence of wild boar poaching has been generated using DNA profiling to match blood on the defendant's knife to a wild boar carcass (Lorenzini 2005).

Individual DNA profiles can also be used to regulate the legal trade in species that are protected in only part of their range, or are subject to strict quotas. Wildlife DNA registers in which legally traded specimens can be individually recognized through a DNA profile, provide a method of ensuring that illegally obtained wildlife cannot be laundered into a legitimate supply chain. This has been demonstrated in principle for the minke whale Balaenoptera acutorostrata by comparing samples obtained from markets to an existing Norwegian genetic register of legally caught whales (Palsbøll et al. 2006). An adaptation of this approach is already applied in south-east Asia to verify the source of merbau Intsia spp., a tropical hardwood traded under quota. DNA profiles are produced for each tree stump in a concession and stored on a database. Logs and timber products originating from that concession are subsequently resampled throughout shipment and processing. Illegally laundered wood can be identified via DNA profile exclusion from the original tree stumps (Lawson 2007). This type of innovative approach can provide forensic evidence for enforcing trade controls, but importantly also offers a method for self-regulation, allowing limited enforcement resources to be more efficiently deployed elsewhere. However DNA registers are not without controversy. The ability to individually identify tigers using DNA profiles has been used to support the argument for tiger farms in China, by demonstrating that animal bones and skins originate from captive sources. In such endangered species, any level of legal trade may threaten the survival of those remaining in the wild by supporting a lucrative market and incentivising poachers. 


\section{Familial identification}

The ability to verify or refute familial relatedness is the fourth principle application of wildlife DNA forensic techniques. Establishing levels of relatedness is important for many aspects of conservation genetics, but for forensic investigation the focus lies primarily on the differentiation of captive bred from wild caught animals. Captive breeding programmes are now commonplace throughout the world and focus on either sustaining global populations of highly endangered species, or the production of animals and plants of commercial value. Problems arise when the 2 drivers cross-over, as they often do, and rare species become highly prized commodities with large profits to be made from their commercial trade. This situation may lead to unscrupulous 'breeders' laundering animals or plants taken from the wild and re-selling them as captive bred individuals. Examples of current issues include the trade in parrots, birds of prey, tortoises and orchids.

The fact that genetic markers are inherited from one generation to the next allows DNA profiles to be used to verify parent-offspring relationships. The alleles present in the DNA profile of an individual must also be present in its putative parents, 1 allele per marker in each parent. If alleles are observed that do not correspond to those in the putative parental profiles, then the possibility of the individual being their offspring can be excluded. This method of profile exclusion to refute parentage claims, like individual sample matching, does not require profile data from the wider population and is therefore relatively simple to apply. However, the results of parental exclusion are not as definitive as those for individual profile exclusion and require more interpretation. The basis of variability at a genetic marker is the occurrence of heritable mutation events, where 1 allele changes to another between generations. Although such events rarely occur, they do create the possibility that disagreement between parent and offspring profiles may be due to mutation rather than false parentage. Ideally, as in human genetics, the mutation rate at each marker should be incorporated into parentage analysis; however, this is rarely possible for wildlife species, and profile interpretation therefore requires caution.

A number of forensic DNA profiling systems have been developed specifically for parentage verification. In the UK, where the theft of chicks from wild nest sites persists, genetic tools have been used to investigate captive breeding claims in a number of birds of prey species for the past 20 yr (Wetton \& Parkin 1997; reviewed by Shorrock 1998). The techniques used have evolved in parallel to human forensic genetic techniques, resulting in the recent development of microsatellite DNA profiling systems for 6 different species (Dawnay et al. 2008). Similar systems are employed throughout Europe and Australia to verify captive bird breeding, while in Russia, parentage analysis is used to authenticate caviar produced from captive sturgeon (S. Rastorguev pers. comm.). Wildlife DNA forensic approaches offer a powerful way to investigate wild animal laundering and are set to become more widely used as conservation enforcement increases.

\section{Sample types for DNA analysis}

The successful recovery of DNA from biological evidence is the most important stage in any forensic genetic investigation. The diversity of DNA sources available to human forensic scientists has been well publicized and includes soft body tissues, bones, teeth, hair, saliva, sweat, urine and faeces. The methods used to extract DNA from these sample types can often be transferred to other species; however, wildlife forensic geneticists may be faced with quite different sample types such as fish scales, feathers, fruits or processed timber. Conservation geneticists have developed techniques for recovering DNA from a remarkable array of sample types (e.g. snake venom, Pook \& McEwing 2005; moulted feathers, Horvath et al. 2005; fish scales, Kumar et al. 2007; porcupine quills, Oliveira et al. 2007; historic eggs, Lee \& Prys-Jones 2008), enabling genetic information to be recovered from almost any biological material.

Sample types can be characterized in terms of the quantity of DNA initially present, its protection from environmental degradation and the ease with which purified DNA can be recovered. For example, hard materials such as bone, tooth, horn and ivory may contain relatively little DNA, which is difficult to extract, but which is preserved in the sample for many years (Yang et al. 1998). In contrast, soft tissues tend to contain more DNA which is simple to recover, but which is prone to rapid decomposition. Plant tissues also vary widely in composition, and different techniques need to be used when dealing with root fibres, leaves, fruit and seeds or solid timber.

One of the particular problems associated with DNA recovery from wildlife samples is environmental degradation due to bacterial breakdown, physical destruction, or damage from natural UV light (Lindahl 1993). Another complication to DNA recovery is that crimes against wildlife often involve the illegal trade in processed parts and derivatives, such as in TMs, and the investigator is often faced with needing to identify heavily treated sample types containing multiple individuals' or species' DNA (Gill et al. 2006, Tobe \& Linacre 2008). 
The type and quality of biological evidence obtained during an investigation affects the DNA analysis that can be subsequently applied. Very low quantities of cellular material may limit analysis to mitochondrial or chloroplast DNA. Degraded DNA will fragment, restricting analysis to small target sequences. Although processes such as 'whole genome amplification' are now being applied to increase the success rate of non-human genetic analysis (authors' unpubl. data), the quality and quantity of DNA recoverable from the sample type is critical to downstream applications. The implications for wildlife crime investigations are that there is a higher success rate for techniques that rely on mitochondrial markers, such as species identification, and techniques that target short fragments of DNA, such as SNP genotyping.

The diverse range of identification questions that can be addressed using genetic methods offers great potential to forensic investigation and wildlife law enforcement. However, in order to reach the stage of presenting evidence to an enquiry or prosecution, a large number of practical issues surrounding the production and interpretation of genetic evidence must be considered. The following section examines key areas in the transfer from conservation genetic research to forensic genetic application.

\section{FROM RESEARCH TO APPLICATION}

The term 'forensic' is becoming something of a buzzword in the conservation genetic community. The potential to transfer research applications into investigative tools is receiving enthusiastic recognition from government agencies, non-governmental organizations and academic scientists. Furthermore, an increasing number of publications are associating biological research with the field of forensic science through claims regarding the potential application of their findings. While an increased focus on the subject of wildlife forensics helps to raise the profile of the field, it also risks blurring the boundaries between academic and forensic sciences. While many wildlife forensic genetic techniques have developed directly from conservation research, it is important to draw a clear distinction between the production of data for research purposes and the generation of evidence destined for court.

Most recent wildlife 'forensic' genetic research can be placed into 1 of 3 categories. First, there are technical papers describing novel methods or newly isolated genetic markers which detail their potential applications to forensic casework or trade monitoring (e.g. Fitzsimmons et al. 2001, Jones et al. 2002, Moore et al. 2003, Rodzen et al. 2007). This research pro- vides the fundamental tools for the genetic identification of wildlife. Second, there are research papers that describe the use of molecular genetic techniques to monitor illegal persecution or trade in endangered species (e.g. Roman \& Bowen 2000, Wasser et al. 2004, Withler et al. 2004). Such work helps to develop initial tools into practical applications, while the resulting survey data play an important role in highlighting threats to endangered species and provide useful intelligence to enforcement investigations. Third, there are papers that describe the validation of tools used to generate data of evidential quality (e.g. Gilson et al. 1998, Branicki et al. 2003, Dawnay et al. 2007, 2008b). While all 3 research areas are effective components of conservation genetics, only techniques falling into the last group are sufficient for application to forensic investigations requiring evidential data. What distinguishes this work from tool development and genetic monitoring is the level of validation, quality assurance (QA) and quality control (QC) supporting the research.

In any enforcement application, all processes of data production and interpretation may be subject to challenge. Sample collection and transfer, laboratory and statistical analyses, the accuracy of the reference database and the presentation of findings are all scrutinized by lawyers and scientists searching for potential sources of doubt in the evidence. It is therefore essential that each stage of the method is assessed and validated prior to enforcement use. 'Validation' is broadly defined as the process by which the scientific community acquires the necessary information to (1) assess the ability of a procedure to obtain reliable results, (2) determine the conditions under which such results can be obtained, and (3) define the limitations of the procedure (SWGDAM 2003). The validation process identifies the methodological aspects that are critical to the production of evidential data. While validation studies are embedded within the development of human forensic genetic methods, they are often overlooked in the transfer of conservation genetic research to wildlife forensic application. The Scientific Working Group on DNA Analysis Methods (SWGDAM) has identified 2 aspects of validation; developmental and internal. Developmental validation involves demonstration of the accuracy, precision, and reproducibility of a procedure and must be carried out prior to its use in forensic casework. This is achieved by performing studies specifically designed to question the novel technology's reliability and limitations. Internal validation is conducted by each testing laboratory and is the 'in-house' demonstration of the reliability and limitations of the procedure (SWGDAM 2003). Elements of data production that require validation are briefly introduced here. 


\section{Sample collection and transfer}

Choice of sample type and methods of sample collection, storage and transfer are extremely important. Validation studies are required to demonstrate that different sample types can be reliably used for analysis, covering various alternative source materials such as moulted feathers, ivory, faeces and processed timber, different production processes including cooking, tanning, and mixing with other species products and the effects of environmental DNA degradation. The chain of custody that links sample collection to result interpretation must follow a documented procedure applied by all agencies involved, to ensure that all transfer and storage of samples is secure and that evidence tampering is detectable. If evidential integrity can be successfully challenged, subsequent forensic analysis is irrelevant.

\section{Laboratory analysis}

A wide range of DNA extraction chemistries and platforms are commonly used in genetics laboratories, some of which have been validated (e.g. Nagy et al. 2005), many of which have not. Selection of a validated method, or performance of a validation study, should be undertaken in order to demonstrate the reliability of the technique to recover DNA of sufficient quality and quantity for subsequent analysis. Many of the most common genetic analysis techniques (e.g. Wilson et al. 1995, Moretti et al. 2001) and platforms (e.g. Lygo et al. 1994, Koumi et al. 2004) have been validated for forensic use; however, it should be noted that some early markers such as multi-locus probes and RAPDs are now widely considered inappropriate, while state-of-the-art array-based genotyping platforms have yet to undergo formal validation. The key area for validation in the laboratory comes in the development of genetic markers used to provide information about the sample. Generic markers commonly used for species identification have been validated, such as mitochondrial gene regions within cytochrome $b$ (Branicki et al. 2003) and cytochrome oxidase I (Dawnay et al. 2007). However, the vast majority of nuclear markers used for population assignment and individual identification have been transferred directly from a research environment. In such cases, validation is required to demonstrate that alleles can be unambiguously identified, that markers exhibit Mendelian inheritance and are independent of one another, and that variation in analytical conditions does not affect the genotype produced. Guidelines for molecular marker validation are available for human systems (SWGDAM 2003) and these should be transferred to non-human species as comprehensively as possible (e.g. Coomber et al. 2007, Dawnay et al. 2008b).

\section{Statistical analysis}

Species identification is generally performed using sequence similarity matches that often indicate a single species of origin. While the associated sequence matching algorithms have been peer-reviewed (Altschul et al. 1997, Ratnasingham \& Hebert 2007) and the resulting data still require interpretation, they do not normally require further analysis. Population assignment and individual or familial identification may also result in the categorical identification or exclusion of a sample; however, data are more commonly described probabilistically, based on statistical analysis of the observed DNA profiles. For geographic origin identification, there are a number of possible statistical approaches and barring rare examples (e.g. Phillips et al. 2007), there is no precedent available from human applications to direct the choice of method. The methods and assumptions used to identify the most likely source population must be critically evaluated in the context of each individual case (for a review, see Manel et al. 2005). In contrast, individual and familial identification benefit from the transfer of established human forensic statistical methods (Evett \& Weir 1998, Balding 2005). However, important differences exist between human and non-human systems, particularly relating to levels of inbreeding (Ayres \& Overall 1999, Waits et al. 2001) which require explicit consideration.

\section{Reference data}

All genetic identification techniques rely on reference data, either to match unknown against authenticated samples, or to provide population data for probabilistic assignment. The reliability of results derived from any database are dependent on data quality; validation of reference datasets is therefore of fundamental importance (Parson et al. 2004). This is being achieved through initiatives such as CBOL, in which species diagnostic DNA sequences are linked through an audit trail to authenticated reference source material. This approach reduces the risk of data error compared to the NCBI/EMBL/DDBJ databases and is recommended for the construction of localized reference data sets. Validation of reference data for population and individual identification relies on accurate inter-laboratory allelic identification, which has limited the exchange and development of these techniques in wildlife forensics. However, reference datasets have been successfully produced, for example for NW Pacific salmon (Seeb et al. 2007) and UK badgers (Dawnay et al. 2008b), and clear guidelines are available for allele nomenclature systems and population data publication (Bär et al. 1997, Lincoln \& Carracedo 2000). 
Despite their importance, validation studies on novel techniques and genetic markers are not universally performed or documented by laboratory staff conducting forensic casework on wildlife species and are mistakenly assumed to be time-consuming, expensive and best suited for summer interns (Butler 2006). The development of formalized recommendations and guidelines for forensic animal identity testing (e.g. Budowle et al. 2005, Dawnay et al. 2008b) may aid the adoption of such practices by those performing wildlife forensic genetic casework. Additional useful information regarding validation and experimental methodology can be found in many human-based forensic research papers (e.g. Andersen et al. 1996, Moretti et al. 2001, Butler 2006) and web resources (STRBase, www.cstl.nist.gov/ biotech/strbase/validation.htm).

In addition to acknowledging differences between the development of techniques to provide genetic data for research and enforcement, it is also important to recognize the importance of the laboratory environment in which sample testing is to be undertaken. Analysis of forensic evidence samples should be restricted to laboratories that are able to manage projects and conduct tests in accordance with auditable standards. QA systems demonstrate the ability of a laboratory to provide accurate, reproducible and secure results. While the lack of laboratory accreditation does not prevent scientists from performing forensic casework, it may result in legal challenges to the evidence that prevent admission to court. Genetic QA practices include adherence to strict chain of custody procedures, complete separation between pre- and postPCR facilities, ongoing equipment calibration and regular internal and external audits of all analytical processes. It should be noted that in many countries, all notebooks, spreadsheets and emails relating to a case are admissible as evidence and are therefore included in QA systems. Useful information regarding QA and QC practices are made by forensic working groups such as the European DNA Profiling Group (EDNAP) the International Society of Forensic Genetics (ISFG), the Scientific Working Group on DNA Analysis Methods (SWGDAM) and the DNA Advisory Board (DAB).

The emphasis placed on QA and QC in forensic science is greater than in conservation genetic research. This fact does not discredit academic research or imply that results from forensic laboratories are necessarily more accurate, but it recognizes the different questions asked by each field. While conservation genetic research often looks for patterns within populations, forensic casework is concerned with the degree of certainty of identification from a single sample. Performing validation studies and adhering to laboratory QA and QC increase data confidence for both practitioners and the legal community and are the difference between generating data for conservation genetic research and providing forensic evidence.

\section{Presentation of evidence}

Alongside the practical aspects of method validation and quality assurance, the role of the scientist also differs between wildlife DNA forensics and conservation genetic research. In most wildlife crime investigations, forensic analysis will have been requested by the authorities responsible for prosecuting the case; however, the role of the forensic practitioner is always to provide evidence for the benefit of the court, rather than the prosecution or defence. It is therefore essential that the presentation of analytical results, as well as being communicated for non-scientists, is seen to be completely impartial. To achieve this, the forensic scientist must objectively evaluate the evidence under both the prosecution and defence hypotheses relating to the allegation and describe the relative likelihood of the observed evidence under each scenario. This represents a different point of departure to the academic experimental model where a single scientific theory is proposed and tested using null and alternative hypotheses.

The most widely accepted approach for evaluating DNA evidence is to utilize Bayes' theorem that allows the uncertainty surrounding the hypothesized event to be updated through the addition of the DNA evidence given a specific set of circumstances (see Evett \& Weir 1998). This allows the findings to be presented in the form of a likelihood ratio that quantitatively describes the difference between the likelihood of the prosecution and defence hypotheses. For example, in the case of a DNA profile match between blood on a suspect's knife and a poached tiger carcass, the prosecution hypothesis will state that the profiles are identical because the samples come from the same individual (the victim), while the defence hypothesis will state that the profiles are identical by chance. The forensic analyst must then calculate the probability of observing the evidence, given the available circumstantial information, under each hypothesis (Box 2). In this example, it leads to a large likelihood ratio (LR = 312500 ) that indicates very strong support for the evidence under the prosecution hypothesis. It is important to note that findings are presented in terms of the likelihood of the evidence, not an evaluation of which hypothesis is correct; that is the role of the judge or jury. The Bayesian approach is particularly useful when dealing with quantitative probabilistic data such as individual or population level identification; however it is also a good approach to take for species identification as it protects forensic scientists from 
Box 2. Introduction to likelihood ratios for the evaluation of DNA evidence

When matching DNA profiles in a wildlife crime investigation, it is conventional to use Bayes' theorem to help evaluate the relative likelihood of the two opposing hypotheses, $H_{\mathrm{p}}$, the prosecution hypothesis and $H_{\mathrm{d}}$, the defence hypothesis. Bayes' theorem can be applied when considering how the statistical odds for the occurrence of an event may be affected by the subsequent addition of new information. This of great use when incorporating DNA evidence into an evaluation of the odds associated with a criminal investigation where there is uncertainty surrounding the actual events. The odds form of Bayes' theorem is:

$$
\text { Posterior odds }=\text { Likelihood ratio } \times \text { Prior odds }
$$

This can be written in the context of DNA profile evidence as:

$$
\frac{\mathrm{P}\left(H_{\mathrm{p}} \mid E, I\right)}{\mathrm{P}\left(H_{\mathrm{d}} \mid E, I\right)}=\frac{\mathrm{P}\left(E \mid H_{\mathrm{p}}, I\right)}{\mathrm{P}\left(E \mid H_{\mathrm{d}}, I\right)} \times \frac{\mathrm{P}\left(H_{\mathrm{p}} \mid I\right)}{\mathrm{P}\left(H_{\mathrm{d}} \mid I\right)}
$$

where the first term is the posterior odds, or the probability of $H_{\mathrm{p}}$ relative to $H_{\mathrm{d}}$, given the DNA evidence, $E$, and other circumstances of the case, $I$. The posterior odds are what the court evaluates at the end of trial. The second term is the likelihood ratio, or the ratio of probabilities of the DNA evidence under either hypothesis; this what the forensic investigator must evaluate. The third term describes the odds prior to the inclusion of the DNA evidence.

The aim of the forensic scientist is to calculate the likelihood ratio (LR). In the case of matching 2 DNA profiles, this is achieved by separating the evidence, $E$, into the 2 DNA profiles observed, the crime scene (victim) profile, $G_{C}$, and the trace evidence profile connected to the suspect, $G_{S}$ :

which expands to:

$$
\mathrm{LR}=\frac{\mathrm{P}\left(G_{\mathrm{C}}, G_{\mathrm{S}} \mid H_{\mathrm{p}}, I\right)}{\mathrm{P}\left(G_{\mathrm{C}}, G_{\mathrm{S}} \mid H_{\mathrm{d}}, I\right)}
$$

$$
\mathrm{LR}=\frac{\mathrm{P}\left(G_{\mathrm{S}} \mid G_{\mathrm{C},} H_{\mathrm{p}}, I\right)}{\mathrm{P}\left(G_{\mathrm{S}} \mid G_{\mathrm{C}}, H_{\mathrm{d}}, I\right)} \times \frac{\mathrm{P}\left(G_{\mathrm{C}} \mid H_{\mathrm{p}}, I\right)}{\mathrm{P}\left(G_{\mathrm{C}} \mid H_{\mathrm{d}}, I\right)}
$$

The right hand term concerns the probability of observing the victim profile, $G_{C}$ in the population. This is not conditional on either hypothesis; therefore this term can be cancelled out:

$$
\mathrm{LR}=\frac{\mathrm{P}\left(G_{\mathrm{S}} \mid G_{\mathrm{C}}, H_{\mathrm{p}}, I\right)}{\mathrm{P}\left(G_{\mathrm{S}} \mid G_{\mathrm{C}}, H_{\mathrm{d}}, I\right)}
$$

In the case of matching profiles $\left(G_{\mathrm{S}}=G_{\mathrm{C}}\right)$ the top line of Eq. 5 represents the probability of observing the trace evidence profile, $G_{\mathrm{S}}$, if it originated from the victim with profile $G_{\mathrm{C}}$, which is logically equal to 1 , giving:

$$
\mathrm{LR}=\frac{1}{\mathrm{P}\left(G_{\mathrm{S}} \mid G_{\mathrm{C}}, H_{\mathrm{d}}, I\right)}
$$

The bottom line represents the probability of observing the trace evidence profile, $G_{\mathrm{S}}$, if it originated from another individual in the population. If we assume that the source of the trace evidence is unrelated to the victim, $G_{\mathrm{C}}$, then this term $\left(G_{\mathrm{C}}\right) \mathrm{can}$ be eliminated, to leave $\mathrm{P}\left(G_{\mathrm{S}} \mid H_{d r} I\right)$, which can be equated to the probability of observing a second identical profile in the population (match probability). Therefore the likelihood ratio that allows the forensic investigator to evaluate the probability of the evidence under the prosecution and defence hypotheses is:

$$
\mathrm{LR}=\frac{1}{\text { Match probability }}
$$

In a practical example, consider an investigation in which a bear has been poached and skinned. Several months later, a bear skin is offered for sale on the internet by a man known to have been hunting in the area around the time the bear was killed. Wildlife investigators obtain a sample of the skin, which the seller claims was from a different bear legally hunted the previous year, and submit the sample for DNA profiling. The profile from the skin matches that of the poached bear. Based on allele frequencies for the regional bear population, the match probability for the profile is calculated as $3.2 \times 10^{-6}$. The prosecution alleges that the bear skin originated from the poached bear $\left(H_{\mathrm{p}}\right)$, the defence claims that the skin originated from another bear, which has since been destroyed $\left(H_{\mathrm{d}}\right)$.

The DNA evidence is evaluated by calculating the likelihood ratio (Eq. 8):

$$
\mathrm{LR}=\frac{\mathrm{P}\left(G_{\mathrm{S}} \mid G_{\mathrm{C}}, H_{\mathrm{p}}, I\right)}{\mathrm{P}\left(G_{\mathrm{S}} \mid G_{\mathrm{C}}, H_{\mathrm{d}}, I\right)}
$$

The probability of observing the evidence profile assuming $\mathrm{H}_{\mathrm{p}}$ is true, is equivalent to the probability that 2 samples from the same bear have the same profile, which is equal to 1 . The probability of the evidence assuming $H_{\mathrm{d}}$ is true, is the probability that a second bear in the population has the same profile as that already observed in the poached animal, which for unrelated animals is equal to the match probability $\left(3.2 \times 10^{-6}\right)$. Therefore the likelihood ratio becomes:

$$
\frac{1}{3.2 \times 10^{-6}}=312500
$$

That is, the evidence is 312500 times more likely under $H_{\mathrm{p}}$, than under $H_{\mathrm{d}}$, providing very strong support that the skin originated from the poached bear.

For a more comprehensive explanation of how Bayes' theorem is applied to interpret matching DNA profile data, see Evett \& Weir (1998), or Balding (2005). 
allegations of bias and ensures that they have considered possible alternatives.

\section{LIMITATIONS OF FORENSIC DNA ANALYSIS}

As with any other technique, DNA analysis does not offer solutions to every type of question posed in a forensic investigation. It is therefore important to acknowledge the limitations of genetic identification and to be aware of complementary or alternative approaches. In relation to crime involving endangered species, there are 2 issues that routinely need addressing in investigations for which DNA analysis is of no real use, i.e. ageing samples and determining the geographic origin of captive/cultured specimens.

Estimating the age of samples is often required in order to date specimens such as ivory, horn or timber originating from protected species. Under CITES regulations, the trade in specimens that pre-date 1947 is not subject to restriction, leading to false claims about the age of traded products. DNA analysis alone cannot provide information concerning either the age of the individual organism concerned, or the time at which it lived. Instead, the problem of aging samples with respect to the 1947 cut-off can be addressed through the use of radiocarbon dating. One affect of atmospheric nuclear testing that began in 1952 was to alter the carbon isotope ratio that can be traced through incorporation into organic material. This approach has recently been used in a forensic context to demonstrate that ivory claimed to pre-date 1947 was actually produced by an elephant living post-1952 (G. Cook pers. comm.).

We have reviewed the use of DNA analysis to determine the geographic origin of wild animals and plants, but such applications are of little use when species are transported into captivity outside of their natural range. Questions that subsequently relate to where a sample came from, either range state $\mathrm{A}$, or captivebred state $B$, are confounded due to the presence of the same genetic markers in both regions. In the absence of comparative parental samples to verify captive breeding, it is not possible to use DNA markers to distinguish these alternatives. In such cases, use of environmental markers such as stable isotopes that reflect the locality where the specimen lived are of more use.

Other limitations to the application of wildlife DNA forensics relate to the level of resources available to develop, validate and apply the required techniques. This is particularly true for the identification of geographic origin, individuals and familial relationships, which usually require the production of population genetic databases in addition to the analytical methods themselves. The effectiveness of finite resources can be maximized through careful prioritization together with creative alternatives to direct identification that remove the reliance on database availability. As mentioned earlier, using genetic data to exclude 2 samples from having the same source is much simpler than categorical sample matching or identification. Where possible, therefore, forensic scientists, enforcement officers and legislators should seek to direct investigations towards questions that can be addressed by exclusion. For example, in cases where animals are suspected to have been taken from the wild and laundered as captive bred, DNA analysis can be much more readily used to refute parentage claimed by the defendant than prove wild parentage asserted by the prosecution.

Ultimately, any forensic evidence is only as effective as the enforcement system in which it is applied. The use of forensic genetics in wildlife law enforcement requires a multi-agency approach that will include field officers, investigation agencies and prosecution authorities often from a range of organizations, such as customs, police, national parks, government departments and non-governmental organizations; in addition to forensic scientists. Communication and cooperation among all elements is essential to enable forensic evidence to be successfully collected, stored, transferred, analyzed and presented in court.

\section{FUTURE DEVELOPMENTS AND CHALLENGES}

The future development of wildlife DNA forensics is dependent on the continuation of novel research and technology transfer to address new enforcement issues. It is equally reliant on conservation action by the authorities to formulate new legislation and enforce existing regulations. While specific issues in individual countries are now routinely approached using forensic genetic tools to support enforcement investigations, the full potential of these techniques will only be achieved through the more widespread development of a forensic framework for tackling crime against endangered species.

The rate at which genetic data can now be produced is outstripping our ability to analyze it. Genome sequencing is becoming faster and less expensive, and is being applied to an ever greater number of taxa. While novel technologies are focused on human and model species systems, horizontal transfer is bringing genomic methods within reach of endangered species researchers. This offers great promise for many aspects of conservation genetics (Luikart et al. 2003, Kohn et al. 2006), including the development of novel markers for forensic identification and the subsequent production of reference data. Increased genomic data will not 
only provide larger numbers of traditional genetic markers used for identification, such as neutral SNP and microsatellite markers, but also enable the discovery and application of markers associated with adaptive traits which may allow greater resolution of geographic population identification (Westgaard \& Fevolden 2007). This has potential for areas such as fisheries management where migration among ancestral populations tends to prevent geographic differentiation using neutral markers (Mariani et al. 2005).

Genetic species identification is likely to become routine as validated public access data sets such as the BOLD barcoding database become comprehensively populated. The challenges that remain here are to develop methods for targeting species diagnostic DNA in highly processed or mixed species products. In contrast, identification below the species level will be limited by the availability of population data. Individual datasets have been developed for forensic use (see 'Reference data') and other large projects are underway (e.g. FishPopTrace); however, the inherent difficulty in sampling from endangered populations, combined with a lack of agreed data quality standards, or a cooperative basis for data sharing, remain significant challenges to the widespread application of forensic genetic methods.

The ability to incorporate genetic analysis into investigative procedures is not limited to the availability of laboratory technologies. Genetic methods require a broader forensic framework that begins with securing evidence and ends in the correct presentation of data in court. While individual practitioners may have the knowledge and resources to perform validated tests in a quality assured environment, there needs to be an efficient system of multi-agency communication in place for forensic evidence to be effectively utilized. Examples of coordinated national strategies for wildlife crime investigation exist (UK: Partnership for Action against Wildlife Crime [PAW], www.defra. gov.uk/paw; US: Fish and Wildlife Service [FWS], www.fws.gov/le/) and international resources for helping to improve forensic capacity are being developed (TRACE, www.tracenetwork.org/; Interpol, www.interpol.int/public/EnvironmentalCrime/Wildlife/); however, much more work is needed if benefits from technological progress in wildlife DNA forensics are to be fully realized.

\section{SUMMARY AND RECOMMENDATIONS}

The use of DNA forensics to support conservation began over $20 \mathrm{yr}$ ago and has gradually developed alongside human forensic genetic techniques, conservation genetic applications and strengthening wildlife legislation. The current popularity of the field reflects the increasing availability of DNA analysis, but also highlights the alarming extent to which illegal activity is threatening endangered species. Forensic genetic methods are now used to address questions relating to the identification of species, populations, geographic origin, family relatedness and individual identity, offering a large number of possible investigative tools to enforcement officers worldwide. Wildlife DNA forensics is heavily dependent on conservation genetic research for the development of novel techniques and production of reference datasets; however, it is vital that a distinction is made between applied conservation genetics and any extension to forensic genetic investigation. The credibility of any forensic application relies on being able to demonstrate evidential security and the validity of the laboratory technique, data analysis and interpretation of results. These issues must be addressed during the transfer from research approaches to forensic tools. The increasing availability of genomic data is set to rapidly expand our potential to develop and apply wildlife DNA forensic techniques. However, in order to ensure that future research is successfully converted into practical applications for law enforcement, wildlife forensic practitioners must aim to meet the same rigorous quality standards achieved in human DNA forensics. With this in mind, the following recommendations are made for conducting wildlife DNA forensic science. To successfully apply wildlife DNA forensic techniques it is recommended that: (1) Scientists consider the need to act impartially, (2) Genetic identification methods are validated prior to forensic use, (3) Genetic analysis is performed in a quality assured environment that controls sample integrity, test performance, data interpretation and evidence presentation.

To further develop the field of wildlife DNA forensics we call for: (1) Greater coordination and exchange of validated population data, reference samples and protocols, (2) Establishment of a network of accredited wildlife DNA forensic laboratories, (3) Directed research to address specific conservation law enforcement needs.

Acknowledgements. The authors are grateful for the comments of 3 anonymous reviewers which helped to improve this manuscript.

\section{LITERATURE CITED}

Altschul SF, Madden TL, Schaffer AA, Zhang JH, Zhang Z, Miller W, Lipman DJ (1997) Gapped BLAST and PSIBLAST: a new generation of protein database search programs. Nucleic Acids Res 25:3389-3402

> Andersen JF, Greenhalgh MJ, Butler HR, Kilpatrick SR and others (1996) Further validation of a multiplex STR system for use in routine forensic identity testing. Forensic Sci Int 78:47-64 
Avise JC (1994) Molecular markers, natural history and evolution. Chapman \& Hall, New York

Ayres KL, Overall ADJ (1999) Allowing for within-subpopulation inbreeding in forensic match probabilities. Forensic Sci Int 103:207-216

Baker CS, Palumbi SR (1994) Which whales are hunted? A molecular genetic approach to monitoring whaling. Science 265:1538-1539

Baker CS, Cipriano F, Palumbi SR (1996) Molecular genetic identification of whale and dolphin products from commercial markets in Korea and Japan. Mol Ecol 5:671-685

Balding DJ (2005) Weight of evidence for DNA profiles. John Wiley \& Sons, Chichester, UK

Bär W, Brinkmann B, Budowle B, Carracedo A and others (1997) Further report of the DNA commission of the ISFH regarding the use of short tandem repeat systems. Int $\mathrm{J}$ Legal Med 110:175-176

Bär W, Brinkmann B, Budowle B, Carracedo A and others (2000) Guidelines for mitochondrial DNA typing. Vox Sang 79:121-125

Benson S, Lennard C, Maynard P, Roux C (2006) Forensic applications of isotope mass spectrometry-a review. Forensic Sci Int 157:1-22

Branicki W, Kupiec T, Pawlowski R (2003) Validation of cytochrome $b$ sequence analysis as a method of species identification. J Forensic Sci 48:83-87

Budowle B, Allard MW, Wilson MR, Chakraborty R (2003) Forensics and mitochondrial DNA: applications, debates, and foundations. Annu Rev Genomics Hum Genet 4: $119-141$

Budowle B, Garofano P, Hellman A, Ketchum M and others (2005) Recommendations for animal DNA forensic and identity testing. Int J Legal Med 119:295-302

Burke T, Bruford MW (1987) DNA fingerprinting in birds. Nature 327:149-152

Butler JM (2006) Debunking some urban legends surrounding validation within the forensic DNA community. Profiles in DNA 9:3-6

Butler JM, Levin BC (1998) Forensic applications of mitochondrial DNA. Trends Biotechnol 16:158-162

> Butler JM, Shen Y, McCord BR (2003) The development of reduced size STR amplicons as tools for analysis of degraded DNA. J Forensic Sci 48:1054-1064

> Carracedo A, Bar W, Lincoln P, Mayr W and others (2000) DNA commission of the international society for forensic genetics: guidelines for mitochondrial DNA typing. Forensic Sci Int 110:79-85

> Chapman DD, Abercrombie DL, Douady CJ, Pikitch EK, Stanhope MJ, Shivji MS (2003) A streamlined, biorganelle, multiplex PCR approach to species identification: application to global conservation and trade monitoring of the great white shark, Carcharodon carcharias. Conserv Genet 4:415-425

> Coomber N, David VA, O'Brian SJ, Menotti-Raymond M (2007) Validation of a short tandem repeat multiplex typing system for genetic individualization of domestic cat samples. Croat Med J 48:547-555

Cronin MA, Palmisciano DA, Vyse ER, Cameron DG (1991) Mitochondrial-DNA in wildlife forensic-science - species identification of tissues. Wildl Soc Bull 19:94-105

Dawnay N, Ogden R, McEwing R, Carvalho GR, Thorpe RS (2007) Validation of the barcoding gene COI for use in forensic genetic species identification. Forensic Sci Int 173:1-6

Dawnay N, Ogden R, Wetton JH, Thorpe RS, McEwing R (in press) (2008a) Genetic data from 28 STR loci for forensic individual identification and parentage analyses in six bird of prey species. Forensic Sci Int: Genet. doi: 10.1016/ j.fsigen.2008.07.001

> Dawnay N, Ogden R, Thorpe RS, Pope LC, Dawson DA, McEwing R (2008b) A forensic STR profiling system for the Eurasian badger: a framework for developing profiling systems for wildlife species. Forensic Sci Int: Genet 2: $47-53$

> Deguilloux MF, Pemonge MH, Petit RJ (2002) Novel perspectives in wood certification and forensics: dry wood as a source of chloroplast, mitochondrial and nuclear DNA. Proc R Soc Lond B Biol Sci 269:1039-1046

> DeSalle R, Birstein VJ (1996) PCR identification of black caviar. Nature 381:197-198

Evett IW, Weir BS (1998) Interpreting DNA evidence: statistical genetics for forensic scientists. Sinauer Associates, Sunderland, MA

Fitzsimmons NN, Tanksley S, Forstner MRJ, Louis EE, Daglish R, Gratten J, Davis S (2001) Microsatellite markers for Crocodylus: new genetic tools for population genetics, mating system studies and forensics. In: Grigg GC, Seebacher F, Franklin CE (eds) Crocodilian biology and evolution. Surrey Beatty \& Sons, Chipping Norton, p 51-57

Frankham R, Ballou JD, Briscoe DA (2002) Introduction to conservation genetics. Cambridge University Press, Cambridge

Gill P, Jeffreys AJ, Werrett DJ (1985) Forensic applications of DNA 'fingerprints'. Nature 318:577-579

Gill P, Brenner CH, Buckleton JS, Carracedo A and others (2006) DNA commission of the International Society of Forensic Genetics: recommendations on the interpretation of mixtures. Forensic Sci Int 160:90-101

Gilson A, Syvanen M, Levine K, Banks J (1998) Deer gender determination by polymerase chain reaction: validation study and application to tissues, bloodstains, and hair forensic samples from California. Calif Fish Game 84: 159-169

Guglich EA, Wilson PJ, White BN (1994) Forensic application of repetitive DNA markers to the species identification of animal tissues. J Forensic Sci 39:353-361

Gupta SK, Verma SK, Singh L (2005) Molecular insight into a wildlife crime: the case of a peafowl slaughter. Forensic Sci Int 154:214-217

Hajibabaei M, Smith MA, Janzen DH, Rodriguez JJ, Whitfield JB, Hebert PDN (2006) A minimalist barcode can identify a specimen whose DNA is degraded. Mol Ecol Notes 6:959-964

> Hauser L, Seamons TR, Dauer M, Naish KA, Quinn TP (2006) An empirical verification of population assignment methods by marking and parentage data: hatchery and wild steelhead (Oncorhynchus mykiss) in Forks Creek, Washington, USA. Mol Ecol 15:3157-3173

Hebert PDN, Ratnasingham S, deWaard JR (2003a) Barcoding animal life: cytochrome $C$ oxidase subunit 1 divergences among closely related species. Proc R Soc Lond Ser B Biol Sci 270(Suppl 1):96-99

Hebert PDN, Cywinska A Ball SL and deWaard JR (2003b) Biological identifications through DNA barcodes. Proc R Soc Lond Ser B Biol Sci 270:313-321

Hold GL, Russell VJ, Pryde SE, Rehbein H and others (2001) Validation of a PCR-RFLP based method for the identification of salmon species in food products. Eur Food Res Technol 212:385-389

> Holder M, Lewis PO (2003) Phylogeny estimation: traditional and Bayesian approaches. Nat Rev Genet 4:275-284

> Horvath MB, Martinez-Cruz B, Negro JJ, Kalmar L, Godoy JA (2005) An overlooked DNA source for non-invasive genetic analysis in birds. J Avian Biol 36:84-88

Hsieh HM, Huang LH, Tsai LC, Kuo YC, Meng HH, Linacre 
A, Lee JCI (2003) Species identification of rhinoceros horns using the cytochrome $b$ gene. Forensic Sci Int 136:1-11

Imaizumi K, Akutsu T, Miyasaka S, Yoshino M (2007) Development of species identification tests targeting the 16S ribosomal RNA coding region in mitochondrial DNA. Int J Legal Med 121:184-191

Jones KC, Levine KF, Banks JD (2002) Characterization of 11 polymorphic tetranucleotide microsatellites for forensic applications in California elk (Cervus elaphus canadensis). Mol Ecol Notes 2:425-427

Kochzius M, Nölte M, Weber H, Silkenbeumer N and others (2008) DNA microarrays for identifying fishes. Mar Biotechnol 10:207-217

Kohn MH, Murphy WJ, Ostrander EA, Wayne RK (2006) Genomics and conservation genetics. Trends Ecol Evol 21:629-637

Koumi P, Green HE, Hartley S, Jordan D and others (2004) Evaluation and validation of the ABI 3700, ABI 3100, and the MegaBACE 1000 capillary array electrophoresis instruments for use with short tandem repeat microsatellite typing in a forensic environment. Electrophoresis 25:2227-2241

Kress WJ, Wurdack KJ, Zimmer EA, Weigt LA, Janzen DH (2005) Use of DNA barcodes to identify flowering plants. Proc Natl Acad Sci USA 102:8369-8374

Kumar R, Singh PJ, Nagpure NS, Kushwaha B, Srivastava SK, Lakra WS (2007) A non-invasive technique for rapid extraction of DNA from fish scales. Indian J Exp Biol 45:992-997

Lander ES (1989) DNA fingerprinting on trial. Nature 339: 501-505

Lander ES, Budowle B (1994) DNA fingerprinting dispute laid to rest. Nature 371:735-738

Lawson S (2007) Certisource DNA legality assurance system - independent assessment. www.certisource.net/ data+downloads/02_Independent_Certisource_Report_ Summary_09-2007.pdf (accessed on 26 May 2008)

> Lee PLM, Prys-Jones RP (2008) Extracting DNA from museum bird eggs, and whole genome amplification of archive DNA. Mol Ecol Resour 8:551-560

Lincoln P, Carracedo A (2000) Publication of population data of human polymorphisms. Forensic Sci Int 110:3-5

Lindahl T (1993) Instability and decay of the primary structure of DNA. Nature 362:709-715

Lorenzini R (2005) DNA forensics and the poaching of wildlife in Italy: a case study. Forensic Sci Int 153:218-221

> Luikart G, England PR, Tallmon D, Jordan S, Taberlet P (2003) The power and promise of population genomics: from genotyping to genome typing. Nat Rev Genet 4: 981-994

Lygo JE, Johnson PE, Holdaway DJ, Woodroffe S and others (1994) The validation of short tandem repeat (STR) loci for use in forensic casework. Int J Legal Med 107:77-89

Manel S, Gaggiotti OE, Waples RS (2005) Assignment methods: matching biological questions with appropriate techniques. Trends Ecol Evol 20:136-142

> Mariani S, Hutchinson WF, Hatfield EMC, Ruzzante DE and others (2005) North Sea herring population structure revealed by microsatellite analysis. Mar Ecol Prog Ser 303:245-257

Moore MK, Bemiss JA, Rice SM, Quattro JM, Woodley CM (2003) Use of restriction fragment length polymorphisms to identify sea turtle eggs and cooked meats to species. Conserv Genet 4:95-103

Moretti TR, Baumstark AL, Defenbaugh DA, Keys KM, Smerick JB, Budowle B (2001) Validation of short tandem repeats (STRs) for forensic usage: performance test- ing of fluorescent multiplex STR systems and analysis of authentic and simulated forensic samples. J Forensic Sci 46:647-660

> Nagy M, Otremba P, Krüger C, Bergner-Greiner S and others (2005) Optimization and validation of a fully automated silica-coated magnetic beads purification technology in forensics. Forensic Sci Int 152:13-22

Ogden R, McGough HN, Cowan RS, Chua L, Groves M, McEwing R (2008) SNP-based method for the genetic identification of ramin Gonystylus spp. timber and products: applied research meeting CITES enforcement needs. Endang Species Res 9:255-261

Oliveira CG, Martinez RA, Gaiotto FA (2007) DNA extraction from bristles and quills of Chaetomys subspinosus (Rodentia: Erethizontidae) using a novel protocol. Genet Mol Res 6:657-666

Palsbøll PJ, Bérubé M, Skaug HJ, Raymakers C (2006) DNA registers of legally obtained wildlife and derived products as means to identify illegal takes. Conserv Biol 20: $1284-1293$

Parson W, Pegoraro K, Niederstatter H, Foger M, Steinlechner $M$ (2000) Species identification by means of the cytochrome $b$ gene. Int J Legal Med 114:23-28

Parson W, Brandstatter A, Alonso A, Brandt N and others (2004) The EDNAP mitochondrial DNA population database (EMPOP) collaborative exercises: organisation, results and perspectives. Forensic Sci Int 139:215-226

Peppin L, McEwing R, Carvalho GR, Ogden R (2008) A DNA based approach for the forensic identification of Asiatic black bear (Ursus thibetanus) in a traditional asian medicine. J Forensic Sci 53:1358-1362

> Phillips C, Salas A, Sánchez JJ, Fondevila M. Gómez-Tato A, Álvarez-Dios J, Calaza M, Casares de Cal M, Ballard D, Lareu MV, Carracedo A, The SNPforID Consortium (2007) Inferring ancestral origin using a single multiplex assay of ancestry-informative marker SNPs. Forensic Sci Int: Genet $1: 273-280$

> Pook CE, McEwing R (2005) Mitochondrial DNA sequences from dried snake venom: a DNA barcoding approach to the identification of venom samples. Toxicon 46:711-715

> Ratnasingham S, Hebert PDN (2007) BOLD: The Barcode of Life Data System (http://www.barcodinglife.org). Mol Ecol Notes 7:355-364

- Rodzen JA, Banks JD, Meredith EP, Jones KC (2007) Characterization of 37 microsatellite loci in mountain lions (Puma concolor) for use in forensic and population applications. Conserv Genet 8:1239-1241

> Roman J, Bowen BW (2000) The mock turtle syndrome: genetic identification of turtle meat purchased in the south-eastern United States of America. Anim Conserv 3:61-65

Seeb LW, Antonovich A, Banks AA, Beacham TD and others (2007) Development of a standardized DNA database for Chinook salmon. Fisheries 32:540-552

> Shivji M, Clarke S, Pank M, Natanson L, Kohler N, Stanhope M (2002) Genetic identification of pelagic shark body parts for conservation and trade monitoring. Conserv Biol 16:1036-1047

Shorrock G (1998) The success of DNA profiling in wildlife law enforcement. Int J Biosci Law 1:327-341

Singh A, Gaur A, Shailaja K, Bala BS, Singh L (2004) Novel microsatellite (STR) marker for forensic identification of big cats in India. Forensic Sci Int 141:143-147

Sweijd NA, Bowie RCK, Lopata AL, Marinaki AM, Harley EH, Cook PA (1998) A PCR technique for forensic, specieslevel identification of abalone tissue. J Shellfish Res 17: 889-895 
SWGDAM (Scientific Working Group on DNA Analysis Methods) (2003) Revised validation guidelines. www.cstl. nist.gov/div831/strbase/validation/SWGDAM_Validation. doc (accessed on 15 January 2008)

Tahir MA, Caruso JF, Hamby PP, Sovinski SM (1996) Deoxyribonucleic acid profiling by restriction fragment length polymorphism analysis - a compilation of validation studies. Sci Justice 36:173-182

Terol J, Mascarell R, Fernandez-Pedrosa V, Perez-Alonso M (2002) Statistical validation of the identification of tuna species: bootstrap analysis of mitochondrial DNA sequences. J Agric Food Chem 50:963-969

Thommasen HV, Thomson MJ, Shutler GG, Kirby LT (1989) Development of DNA fingerprints for use in wildlife forensic science. Wildl Soc Bull 17:321-326

Tobe SS, Linacre AMT (2008) A multiplex assay to identify 18 European mammal species from mixtures using the mitochondrial cytochrome $b$ gene. Electrophoresis 29:340-347

Verma SK, Singh L (2003) Novel universal primers establish identity of an enormous number of animal species for forensic application. Mol Ecol Notes 3:28-31

Verma SK, Prasad K, Nagesh N, Sultana M, Singh L (2003) Was elusive carnivore a panther? DNA typing of faeces reveals the mystery. Forensic Sci Int 137:16-20

> Waits LP, Luikart G, Taberlet P (2001) Estimating the probability of identity among genotypes in natural populations: cautions and guidelines. Mol Ecol 10:249-256

Wan QH, Fang SG (2003) Application of species-specific polymerase chain reaction in the forensic identification of tiger species. Forensic Sci Int 131:75-78

Wasser SK, Shedlock AM, Comstock K, Ostrander EA, Mutayoba B, Stephens M (2004) Assigning African ele-

Editorial responsibility: Mike Bruford,

Cardiff, UK phant DNA to geographic region of origin: applications to the ivory trade. Proc Natl Acad Sci USA 101: 14847-14852

Westgaard JI, Fevolden SE (2007) Atlantic cod (Gadus morhua L.) in inner and outer coastal zones of northern Norway display divergent genetic signature at non-neutral loci. Fish Res 85:306-315

$>$ Wetton JH, Parkin DT (1997) A suite of falcon single-locus minisatellite probes: a powerful alternative to DNA fingerprinting. Mol Ecol 6:119-128

Wetton JH, Tsang CFS, Roney CA, Spriggs AC (2004) An extremely sensitive species-specific ARMs PCR test for the presence of tiger bone DNA. Forensic Sci Int 140:139-145

Wilson MR, Dizinno JA, Polanskey D, Replogle J, Budowle B (1995) Validation of mitochondrial-DNA sequencing for forensic casework analysis. Int J Legal Med 108:68-74

Withler RE, Candy JR, Beacham TD, Miller KM (2004) Forensic DNA analysis of Pacific salmonid samples for species and stock identification. Environ Biol Fishes 69:275-285

Wong KL, Wang J, But PPH, Shaw PC (2004) Application of cytochrome $b$ DNA sequences for the authentication of endangered snake species. Forensic Sci Int 139:49-55

Wu H, Wan QH, Fang SG, Zhang SY (2005) Application of mitochondrial DNA sequence analysis in the forensic identification of Chinese sika deer subspecies. Forensic Sci Int 148:101-105

$\mathrm{Xu}$ YC, Li B, Li WS, Bai SY and others (2005) Individualization of tiger by using microsatellites. Forensic Sci Int 151: $45-51$

Yang DY, Eng B, Waye JS, Dudar JC, Saunders SR (1998) Technical note: Improved DNA extraction from ancient bones using silica-based spin columns. Am J Phys Anthropol 105:539-543

Submitted: June 23, 2008; Accepted: September 16, 2008 Proofs received from author(s): December 11, 2008 